This item was submitted to Loughborough's Research Repository by the author.

Items in Figshare are protected by copyright, with all rights reserved, unless otherwise indicated.

\title{
Effect of the build orientation on the mechanical properties and fracture modes of SLM Ti-6Al-4V
}

\section{PLEASE CITE THE PUBLISHED VERSION}

http://dx.doi.org/10.1016/j.msea.2014.07.086

\section{PUBLISHER}

(C) Elsevier

VERSION

AM (Accepted Manuscript)

\section{PUBLISHER STATEMENT}

This work is made available according to the conditions of the Creative Commons Attribution-NonCommercialNoDerivatives 4.0 International (CC BY-NC-ND 4.0) licence. Full details of this licence are available at: https://creativecommons.org/licenses/by-nc-nd/4.0/

\section{LICENCE}

CC BY-NC-ND 4.0

\section{REPOSITORY RECORD}

Simonelli, Marco, Yau Tse, and Christopher Tuck. 2014. "Effect of the Build Orientation on the Mechanical Properties and Fracture Modes of SLM Ti-6al-4v". Loughborough University. https://hdl.handle.net/2134/22163. 
Effect of the build orientation on the mechanical properties and fracture modes of SLM Ti-6Al-4V

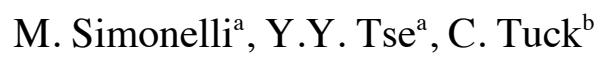

a'Department of Materials, Loughborough University, Loughborough, LE11 3TU, United Kingdom

${ }^{\mathrm{b}}$ Additive Manufacturing and 3D Printing Research Group, Faculty of Engineering, The University of Nottingham, Nottingham, NG7 2RD, United Kingdom

Corresponding author: Marco Simonelli,

email. M.Simonelli@lboro.ac.uk,

Tel. 00447905512054

\begin{abstract}
Recent research on the additive manufacturing (AM) of Ti alloys has shown that the mechanical properties of the parts are affected by the characteristic microstructure that originates from the AM process. To understand the effect of the microstructure on the tensile properties, selective laser melted (SLM) Ti-6Al-4V samples built in three different orientations were tensile tested. The investigated samples were near fully dense, in two distinct conditions, as-built and stress relieved respectively. It was found that the build orientation affects the tensile properties, and in particular the ductility of the samples. The mechanical anisotropy of the parts was discussed in relation to the crystallographic texture, phase composition and the predominant fracture mechanisms. Fractography and electron backscatter diffraction (EBSD) results indicate that the predominant fracture mechanism is
\end{abstract}


intergranular fracture along the grain boundaries present and thus provide and explanation for the typical fracture surface features observed in fracture AM Ti-6Al-4V.

\section{Introduction}

Recent studies have been shown that additive manufacturing (AM) technologies could represent sustainable production routes for metals and, in particular, precious metals such as titanium alloys $[1,2]$. There are several advantages related to the production of titanium components by AM. Firstly, components are produced in their near net shape and therefore AM allows significant reductions in raw material consumption when compared to traditional processing. Furthermore, additive manufactured parts require no or little machining before being put in use, regardless of their shape complexity. Therefore, AM has shown to lower the overall manufacturing costs and carbon emissions [3,4]. Design freedom is the most appealing aspect of AM, especially for the medical and aerospace areas where titanium alloys have been extensively used $[5,6]$. In particular, AM has shown the possibility to fabricate patient specific medical devices (e.g. artificial joint replacements) [7-9] and parts with optimised topology and lattice structures that could replace heavier counterparts currently used in aircrafts [10-13].

With careful choice of process parameters, selective laser melting (SLM) of titanium alloys have shown the possibility to fabricate near fully dense parts [14]. Parts with mechanical properties comparable to those of the conventionally manufactured titanium alloys have also been reported $[15,16]$. As the process stability has shown to be crucial for the production of 
near fully dense products, most of the studies of $\mathrm{CP}-\mathrm{Ti}$ and $\alpha / \beta \mathrm{Ti}$ alloys manufactured by SLM have focussed primarily on the densification mechanisms during the fabrication process [17-20]. Indeed, it has been reported that by combining suitable scan strategy and high laser energy density, it is possible to reduce significantly the volume fraction of defects (i.e. pores) and thus produce near fully dense components $[14,17]$. Microscopy studies have demonstrated that due to the high cooling rates intrinsic to the SLM process, the microstructure of the as-built components consists entirely of $\alpha^{\prime}$ martensitic phase. The $\alpha^{\prime}$ grains are contained within elongated prior- $\beta$ grains that grow epitaxially through successive layer depositions [21-23]. It was observed that this microstructure might not be suitable for most of the current applications of $\alpha / \beta$ Ti alloys as it is typically associated with high strength but poor ductility and possess a certain degree of anisotropy $[21,22,24]$. In order to achieve a better balance between strength and ductility, several SLM post-processing treatments have been introduced, leading to mechanical properties that are much closer to those of conventionally manufactured titanium alloys. However these researches have been conducted on one build orientation only $[16,17]$.

Part quality and mechanical properties (in particular ductility) are however often inconsistent when different SLM systems are used, thus, extensive process development and material testing are still required for the potential establishment of SLM as an alternative manufacturing route of titanium alloys [23-25]. In addition, limited work has been done to show the correlation between the microstructure and the crystallographic texture with the mechanical properties of SLM Ti-6Al-4V. It has been postulated that the residual stresses and the martensitic microstructure of the as-built parts cause low ductility in the SLM Ti-6Al-4V parts [15], whereas the defects are generally considered to be the main contributor to the anisotropic behaviour of the components $[17,21]$. Unfortunately, the contribution of the elongated prior- $\beta$ grains and the $\alpha^{\prime}$ crystallographic texture to the fracture mechanisms in 
SLM Ti-6Al-4V has not yet been illustrated systematically. In addition, most of the available research has focussed only on samples built perpendicular to the build direction and therefore the effect of the building orientation on the mechanical properties remains unclear.

In this study, the mechanical properties of the as-built and stress relieved SLM Ti-6Al-4V samples fabricated in three orthogonal orientations were discussed. By doing so, it was possible to investigate the effect of the building orientation on the mechanical properties and fracture mechanism of the components. This research work also aimed at studying how the stress relieving process modifies the microstructure of SLM Ti-6Al-4V alloys and therefore the tensile properties.

\section{Materials and Methods}

All the samples tested in this research were built using a Renishaw AM250. The starting powder material is a plasma atomised Ti-6Al-4V provided by LPW Technologies Ltd. The powders are spherical, fully dense and consist entirely of $\alpha^{\prime}$ phase. The detailed characterisation was reported elsewhere [26]. A series of experiments was conducted to establish the process window that could lead to a production of near fully dense components. The optimised process parameters and details on the fibre laser that were used in this research are listed in Table 1. The Renishaw AM250 is equipped with a modulated 200W ytterbium fibre laser. In the present research the laser had a spot size of approximately $150 \mu \mathrm{m}$. The speed of the laser was controlled specifying the point distance, i.e. the distance between two successive points in a straight line, and the exposure time, i.e. the duration of time during which the laser dwells on each point. All the samples were built in a protective argon atmosphere and on top of secondary supporting structures. The secondary supporting structures were used for an easier detachment from the build platform once that the production of the parts was completed. The supporting structures were generated 
automatically using the software Magics (Materialise, Belgium). The height of the supports was $3 \mathrm{~mm}$, while the nominal thickness of the individual teeth was $0.2 \mathrm{~mm}$.

The laser scan strategy that was used to melt each layer of powder is reported in a related study [27]. Each layer was scanned once. The laser scanned initially the edge area of each cross section and then the inside area with parallel alternating scan vectors at an angle of $67^{\circ}$ to the previous deposited layer. The laser then scanned the boarder of each cross sections in order to improve the surface roughness of the part and reduce the number of defects near the surface of the component [5].

It is noteworthy that the tensile bars studied in this research were built directly in their nearnet shape and not cut from a block of SLM material as shown in Fig. 1. Two batches with 12 tensile bars were built in total. In accordance with the ASTM F2921, where the orientation of the built part is described listing the axes of the AM machine that are parallel to the longest and second longest dimensions of the part, each batch contained four tensile bars of vertical $z x$-, edge $x z$ - and flat $x y$-orientations (Fig. 1). Excluding the supporting structures, the vertical $z x$-bars consisted of 2000 layers whereas the edge $x z$ - and flat $x y$-oriented bars consisted of 200 and 60 layers respectively. The tensile bars where built with a gauge thickness, width and length of $3 \mathrm{~mm}, 6 \mathrm{~mm}$ and $35 \mathrm{~mm}$ respectively. A batch of tensile bars was heat treated at $730^{\circ} \mathrm{C}$ for $2 \mathrm{~h}$ in a $\mathrm{N}_{2}$ protective atmosphere to relieve all the residual stresses that are reported to occur in the SLM parts [23]. Once the stress relieving was completed, the tensile bars were furnace cooled to room temperature at a cooling rate of $10^{\circ} \mathrm{C} / \mathrm{min}$ (approximately ten times faster than typical furnace cooling rate). The tensile bars were then mechanically polished before the tensile test. This batch of tensile bars will be referred to as "stress relieved condition" in the following sections. The tensile bars which were not stress relieved were also mechanically polished to the same surface finish prior to the tensile test. These tensile bars 
will be referred to as "as-built condition" hereafter. Mechanical polishing was necessary because the surface roughness measured on the horizontal $x y$-planes, i.e. those planes scanned by the laser, differed significantly from the surface roughness measured on the frontal $x z$ - or lateral $y z$ - planes where unmelted powder particles had remained attached to the edge of the sample (Table 2).

Some of the flat orientation bars curled during the building process ripping the supporting structures as a result of the large thermal stresses that typically occur during SLM. Therefore, those curled bars were machined to straight flat bars before being tensile tested. After the machining process, the flat oriented tensile bars had the same gauge length but a smaller gauge thickness $(2 \mathrm{~mm})$ and width $(3 \mathrm{~mm})$, compared to the bars built in the two other orientations.

The tensile tests were performed on an Instron 3369 tensile system (Instron Ltd, Bucks, UK). The test was conducted at room temperature at a displacement rate of $2 \mathrm{~mm} / \mathrm{min}$. Young's modulus, yield stress, ultimate tensile stress and elongation at break were determined according the ASTM E8/E8M using both an extensometer and the measured cross-head strain. The microstructural characterization of the tensile bars and the fracture surface profiles (obtained from sectioning the fracture surfaces normal to the plane of fracture) was carried out on a Nikon Optiphot 100 optical microscope. Backscatter imaging and electron backscatter diffraction (EBSD) maps were acquired by using a Nova 600 Nanolab Dual Beam. EBSD analysis was carried out with a step size of $1 \mu \mathrm{m}$. The prior- $\beta$ phase was reconstructed following the Burgers orientation relationship according to the method detailed elsewhere [27]. Fracture surfaces were investigated mainly using secondary electron imaging 
on a Carl Zeiss (Leo) FEG-SEM. The nature of several fracture features was established using EBSD upon ion milling [28].

Residual stresses on as-fabricated samples were measured in the middle of the frontal cross section ( $x z$-plane) of a $1 \mathrm{~cm}^{3}$ cube at about $1 \mathrm{~mm}$ from the external surface. A Bruker $\mathrm{x}$-ray diffractometer (AXS D8 Advance) equipped with a $\mathrm{K}_{\alpha}(\lambda=0.54 \mathrm{~nm}) \mathrm{x}$-ray point source and a SOL-XE detector was used for the stress analysis. The shift in the diffraction peak position at $2 \theta$ of $142^{\circ}$ due to the residual stresses was measured according to the side inclination method [29]. The peak shifts, that correspond to lattice strains, were measured at three $\phi$ angular rotation $\left(0^{\circ},-45^{\circ}\right.$ and $-90^{\circ}$ respectively $)$ and six $\psi$ tilting angles $\left(0^{\circ}, 9^{\circ}, 18^{\circ}, 27^{\circ}, 36^{\circ}\right.$ and $45^{\circ}$ respectively). Due to the low penetration depth of the x-rays in the material, a plane stress state $\left(\sigma_{33}=0\right)$ was assumed. The stress tensor of the irradiated volume was calculated from the observed lattice strains using a Young modulus of E=115 GPa and a Poisson's ratio v=0.324. As peak shift might be introduced by potential system misalignments during $\psi$ tilting, the experiment was repeated at the same $\psi$ tilting angles and $\phi$ angular rotations on stress free powder material and the stress tensor was in turn calibrated [29].

\section{Results and Discussion}

\subsection{Microstructure and texture of as-built parts and stress relieved SLM Ti-6Al-4V}

The microstructure evolution of SLM Ti-6Al-4V processed in various conditions such as asbuilt, stress relieved, and solution treated has been previously reported in the literature [14, $15,19,21-23]$. The main microstructural features, in particular, porosity, prior- $\beta$ grain boundaries, existing phases, and crystallographic texture will be described as they have a great influence on the mechanical behaviour and crack propagation in Ti alloys [30,31]. As 
the samples showed the same microstructure (i.e. $\alpha^{\prime}$ ( or $\alpha$ ) grain size, prior- $\beta$ grain size and porosity) regardless of their build orientation, the edge oriented specimens were choosen to represent the typical as-built and stress-relieved microstructure of the SLM product

Fig. 2a-c show the microstructure of the edge as-built components on three orthogonal planes (frontal $x z-$, lateral $y z$ - and horizontal $x y$-planes). It is notable that the void defects in the microstructure are randomly distributed (Fig. 2c). Several independent studies have concluded that the defects in SLM or laser welding of $\alpha+\beta$ Ti alloys can originate as a result of non-uniform powder bed preparation (interlayer defects of acicular morphology) or as a consequence of poor $\mathrm{H}_{2}$ solubility in the $\alpha$ lattice $[32,33]$. In this study, it was observed that within the volume of examination the defects density does not vary for parts built in different orientations or distance from the build platform. At room temperature, the microstructure of the as-built components is fully $\alpha^{\prime}$ martensitic and only the vertical grain boundaries of the prior- $\beta$ can be discerned (Fig. 2a-c). Due to the layer-wise nature of the process, the prior- $\beta$ grains grow in a columnar way almost vertically through several layers in the range of $1-3$ $\mathrm{mm}$, while the mid-length average width of the prior $\beta$ grains is $103 \pm 32 \mu \mathrm{m}$ [27]. Therefore, the microstructure on the frontal and lateral planes ( $x z$ - and $y z$-planes) differs significantly from the microstructure on the horizontal planes parallel to the build platform ( $x y$-plane). The microstructure on the frontal $x z$ - and lateral $y z$-planes of the as-built samples is shown in Fig. 2b-c respectively. It was observed that the $\alpha^{\prime}$ grains are generally inclined to the build direction and rarely precipitate on the grain boundary of the prior- $\beta$ grains. The solidification of prior- $\beta$ grains occurred along a direction $\vec{g}$ (growth direction) which is inclined about $20^{\circ}$ to the build direction (z-axis) possibly due to the $67^{\circ}$ laser scan rotation [27].

The microstructure of the samples after stress relief is shown in Fig. 3a-c. As expected, the stress relieving process did not altered the size, morphology or the inclination of the prior- $\beta$ 
grain boundaries as the relieving temperature $\left(730^{\circ} \mathrm{C}\right)$ was much lower than the $\beta$ transus temperature for Ti-6Al-4V [34].

The stress relief heat treatment and furnace cooling have however a significant effect on the phase composition of the specimens. Fig. 4a-b show the grain morphology and phase contrast of the as-built and the stress relieved components. The $\alpha^{\prime}$ grains of the as-built samples span through the width of the prior- $\beta$ grains with a plate-like morphology (average length is $8 \pm 3$ $\mu \mathrm{m}$ and width $0.570 \pm 0.130 \mu \mathrm{m}$ ) as shown in Fig. 4a. The microstructure of the stress relieved samples however consists of a mixture of $\alpha+\beta$ phase, where the $\beta$ phase stands out as the bright contrast phase located at the $\alpha$ laths boundaries of Fig. 4b. The stress relief temperature of $730{ }^{\circ} \mathrm{C}$ allowed the $\alpha^{\prime} \rightarrow \alpha+\beta$ phase transformation to take place [23]. It was observed that the $\alpha$ grains width increased significantly in the stress relieved samples (average length and width are $8.7 \pm 2.4 \mu \mathrm{m}$ and $1.2 \pm 0.3 \mu \mathrm{m}$ respectively). During the stress relief heat treatment coalescence between laths of low grain boundary misorientation might have occurred explaining the $\alpha$ coarsening in the annealed samples.

The crystallographic texture of as-built specimens has been discussed in detail elsewhere [27]. Generally the $\alpha^{\prime}$ phase of the as-built components has a weak texture because of the relatively high number of variants that precipitate within each columnar $\beta$ grain. On the other hand, the reconstruction of the $\beta$ phase texture shows that the columnar grains possess a strong (100) texture in the grain growth direction $\vec{g}$ during solidification [27].

In order to compare the crystallographic texture of the stress relieved edge-oriented samples to that of the as-built components, EBSD on the frontal $x z$ - lateral $y z$ - and horizontal $x y$ planes of the stress relieved parts was carried out. The $\alpha$ orientation maps from the frontal $x z^{-}$, lateral $y z$ - and horizontal $x y$-plane (Fig. 5-7a) indicate that even after the stress relief process no $\alpha$ colonies are present in the microstructure similarly to that observed for SLM Ti-6Al-4V 
in the as-built condition. The corresponding $\alpha$ contour pole figures show that the $\alpha$ texture is weak as a result of the multiple variants that have formed within the $\beta$ columnar grains (Fig.

5-7b). The reconstruction of the crystallographic orientation of the corresponding $\beta$ phase (Fig. 5-7c) shows that the $\beta$ grains grow epitaxially through successive deposited layers. It is clear that the prior- $\beta$ phase has a dominant (100) solidification texture along the grain growth direction (Fig. 5-7d), consistently to that reported for SLM Ti-6Al-4V in the as-built condition [27]. Similar results are reported in laser deposed Ti-6Al-4V where it was noted that the (100) solidification texture along the grain growth direction was maintained after the applied stress relief heat treatment [35].

\subsection{Tensile properties and fracture mechanism of as-built and stress relieved SLM Ti-} 6Al-4V

All the 24 tensile tested samples (12 as-built samples and 12 stress relieved samples from 3 different build directions) failed after a considerable amount of necking in the gauge length of the specimens. The tensile stress-strain curves are shown in Fig. 8a-b and Table 3 summarises the obtained results. The results will be discussed in the following two sections. Section 3.2.1 compares the stress relieved samples to the as-built parts with the same build orientation. Section 3.2.2 describes the effect of the build orientation on the tensile behaviour and fracture mechanism of the specimens.

\subsubsection{Comparison of the tensile properties of stress relieved and as-built SLM Ti-6Al-4V}

The Young's modulus of the stress relieved and as-built samples is consistent for all the tested samples and similar to that reported elsewhere for Ti alloys components made by SLM or other AM technologies $[15,16,36]$. The elastic modulus measured on the as-built bars and stress relieved bars is similar (Table 3). 
Table 3 shows that the yield and ultimate tensile strength (UTS) of SLM Ti-6Al-4V are higher than those of the same alloy produced by conventional processing $[17,37,38]$. This result can be explained by the fact that the onset of plastic deformation is depended on the $\alpha$ colony size, i.e. small colony size delays the onset of the plastic deformation. Both the stress relieved and as-built samples have $\alpha$ (or $\alpha^{\prime}$ ) colony sizes equal to the width of a single $\alpha$ (or $\alpha^{\prime}$ ) laths and therefore display high yield stress. The yield stress and UTS measured on the stress relieved samples is lower than on the as-built samples. This is probably due to the $\alpha^{\prime}$ $\rightarrow \alpha$ phase transformation and the fact that the $\alpha$ laths size has increased after the relatively slow cooling rate after the stress relief heat treatment (Fig. 4a-b). After stress relief, the tensile bars showed both yield stress and UTS comparable to wrought and annealed Ti-6Al4V and exceeded those of cast Ti-6Al-4V [37,38].

Table 3 shows an increase of the elongation at break of all the tensile bars (irrespectively of the built orientation) and hence indicating an improvement in ductility after the stress relief process. It is well known that poor ductility is the major limitation for additive manufactured $\alpha+\beta$ Ti alloys in as-built condition and thus the post processing stress relief heat treatment has proved to be beneficial for SLM Ti-6Al-4V. The difference in ductility between the stress relieved and as-built parts can be explained considering the plasticity of the $\alpha+\beta$ phases [30]. The as-built samples consist entirely of $\alpha^{\prime}$ phase and hence the plastic deformation is mainly restricted to the basal and prismatic slip systems, namely the (0002) $\langle 11 \overline{2} 0\rangle$ and $(10 \overline{1} 0)\langle 11 \overline{2} 0\rangle[30]$. As the $\alpha^{\prime}$ grains do not form colonies of laths sharing the same orientation, the effective slip length is confined to single grains. Thus, the as-built SLM Ti6Al-4V tensile bars show in general a poor elongation at failure. The stress relieved samples, on the other hand, have some retained $\beta$ phase at the grain boundaries of the $\alpha$ laths (Figure $4 b)$. Although the volume fraction of $\beta$ phase is limited, the $\beta$ phase contributes to improve the ductility of the stress relieved samples thanks to slip transfer at the interface of the two 
phases $[39,40]$. Two primary slip systems of the $\alpha$ phase are, in fact, precisely aligned with the $\{110\}\langle 111\rangle$ and $\{112\}\langle 111\rangle$ systems of the $\beta$ phase, with a third set misoriented only $10.5^{\circ}$ and thus, slip transfer across the two phase can occur $[39,40]$. Table 4 shows the stress tensor calculated from the frontal plane of an as-built sample. The normal residual stress components acting on the $x$ - and $z$-axis are 96 and 239 MPa respectively. These values correspond well to those reported in the literature for SLM titanium parts built with an optimised scan strategy [25, 41-43]. Although in this research the distribution of the residual stresses with the height of the sample is not taken into account, $\mathrm{x}$-ray diffraction gives an accurate indication of the high thermal stresses that can be developed during SLM [44]. The internal stresses affect the mechanical performance of the as-fabricated SLM parts regardless of the built orientation and contribute to the poor elongation at break of the as-built samples (Table 3).

\subsubsection{Anisotropy of SLM Ti-6Al-4V: tensile properties of samples with three different build orientations}

Table 3 shows that the elastic modulus does not vary with the build orientation or in other words, that the orientation of the prior- $\beta$ grains has no significant influence on the elastic moduli of the specimens. It has been reported that the $\alpha$ crystal anisotropy has a marked effect of on the elastic modulus of Ti-6Al-4V with a strong crystallographic texture [30]. However, as discussed in section 3.1, all SLM Ti-6Al-4V samples have a weak $\alpha^{\prime}$ (or $\alpha$ ) texture, thus explaining why the elastic moduli do not vary when the build orientation is changed. 
Table 3 shows that the elongation at break of the flat oriented tensile bars is the lowest among the tested samples despite the fact that they have a similar microstructure with the edge oriented samples. This is because the flat bars were built with lower quality (more void defects). The thermal stresses that build up in the flat bars during SLM caused curling of these parts that in turn might have led to uneven powder deposition and hence pore formation. Moreover, in order to have not-curled samples, flat tensile bars were machined to smaller dog bone shape specimens. As the elongation at break is inversely proportional to $\frac{L}{\sqrt{A}}$, where $L$ and A are the initial gauge length and cross-sectional area respectively (ASTM E8/E8M), flat samples showed a reduction in strength and ductility [45]. Because of the possibility of interlayer porosity that can occur during SLM, it was not surprising that the vertical bars consisting of the highest number of layers - have the lowest yield strength and UTS $[17,19]$.

In order to correlate the fracture mechanism and the microstructure of tensile bars built in the different orientations fracture analysis of the tested samples was carried out.

Fig. 9a-c show low magnification SEM images of the fracture surfaces of the stress relieved tensile bars built in different orientations. The fracture surfaces are generally rough and dimpled. The fracture surface profiles corresponding to the fracture of tensile bars built in different orientation are shown in Fig. 10a-c. For all the build orientations, the fracture surface profiles manifest the typical features of overload failures [46]. For the edge and flat samples in particular, the fracture surface profiles consist generally of a central portion relatively flat which is perpendicular to the axial loading, and an external portion (shear lips) that is highly inclined $\left(\sim 45^{\circ}\right)$ to the loading direction (Fig. 10b-c). In addition, the fracture surface profiles reveal that the predominant fracture is inter granular where cracks have propagated mainly along the grain boundaries present in the microstructure as shown in the insets of the same figure. This result is consistent with research on fatigue crack propagation 
of Ti alloys with fine microstructure, where it has been reported that crack propagation is highly depended on the crystallographic orientation of the $\alpha$ grains containing the crack tip and the number of grain boundaries in the microstructure $[40,47,48]$. It has been shown that in fine microstructures the crack tip deflects at the grain boundaries generating predominantly inter granular fracture as the neighbouring $\alpha$ grains (or colonies) have multiple distinct crystallographic orientations (i.e. weak texture) $[31,46,49]$. Ti-6Al-4V with microstructure consisting of $\alpha$ colonies will, on the other hand, give intragranular fatigue fracture $[31,40]$. As SLM Ti-6Al-4V has weak texture, no $\alpha$ colonies (neighbouring $\alpha$ laths with identical orientation), but does have $\alpha$ laths that interface predominately with an high angle boundaries, inter granular fracture is thus the most plausible fracture mode.

From the analysis of Fig. 10a-c, it was observed that the surface roughness of the central portion of the fracture profiles varies according to the build direction and is generally higher in the samples built in the vertical orientation. This results derives from the fact that the vertical tensile bars fractured predominantly either along the $\alpha$ grain boundaries that can span through the width of an entire prior- $\beta$ grain and are generally inclined at $\sim \pm 45^{\circ}$ to the build direction ( $z$-axis) or along prior- $\beta$ grain boundaries. The inset in Fig. 10a shows a typical fracture along the $\alpha$ grain boundary encountered in the vertical oriented tensile bars.

Because the vertical oriented tensile bars have prior- $\beta$ grain boundaries nearly vertical and parallel to the build and loading direction, the fracture along these grain boundaries has generated tortuous crack paths and rougher fracture surface profiles compared to that observed on the other build orientations. The edge and flat oriented bars, on the other hand, have prior- $\beta$ grain boundaries that are nearly perpendicular to loading axis. The inter granular fracture along these boundaries therefore implies less rough fracture surface profiles that are 
generally normal to the loading axis (insets in Fig. 10b-c). These results indicate that higher crack deflection might increase the strength of the vertical oriented bars.

The fracture surfaces were investigated at higher magnification to study the nature of the fracture in detail (Fig. 11a-c). The fracture surface on regions of porosity is smooth and with concentric features indicated by the arrows in Fig. 11b. The morphology is similar to that reported in the literature $[17,25,50]$. As the fracture surface is generally rough, it is difficult to establish whether or not fracture had initiated and propagated predominantly in regions of porosity.

It was observed that terrace-like features are present in all the fracture surfaces despite the build orientation of the tensile bars. An example of terrace-like features (also referred to as layered fracture [19]) is shown in Fig. 11a. Although these features are generally attributed to fracture in regions of porosity $[19,23]$, Fig. $11 \mathrm{~b}$ shows clearly that the terraces have a richer topography than the fractured areas where the powder bed was partially melted and porosity occurred (Fig. 11b). Indeed, it was observed that equiaxed shallow dimples appear on the surface of the terraces similarly to the fracture surface morphology of other high strength metal alloys under tensile loading [46]. Thus, it seems unlikely that the terraces indicated in Fig. 11a are generated from crack propagation on regions of porosity as reported in the literature $[19,23]$. Fracture of laser melted Ti-6Al-4V has been recently discussed and it has been speculated that the terraces might have originated as a result of $\alpha$ cleavage or lamellar fracture $[17,19,24]$. These studies however do not take into account that the terrace size and aspect ratio are more consistent with the prior- $\beta$ grains of the SLM microstructure rather than the $\alpha$ grains that are a one order of magnitude smaller (section 3.1). Similar to this research, it is reported that the elongation at break depends on the orientation of the builds, implying the important role of the prior- $\beta$ boundaries to the fracture mechanism [19]. In 
addition, cleavage fractures occur on defined crystallographic planes with no associated plastic deformation [49]. However, it is clear that the terrace-like features of Fig. 11b-c show dimpled fracture surfaces generated by local plastic deformation.

The morphology of the terraces reveals no clear directional marks, therefore it is difficult to establish with certainty the crack propagation direction. It was observed however that, occasionally, steps can be found on the terrace fracture surfaces as indicated by the arrows of Fig. 11c. It is possible that the steps result as the fracture propagates around $\alpha$ laths of similar orientations that have generated from prior- $\beta$ grains with low angle misorientation [46]. Indeed, from the analysis of the $\alpha$ and $\beta$ orientation maps of Fig. 7, there is evidence that low angle grain boundaries occur during the solidification of SLM Ti-6Al-4V and therefore it is possible that crack tip deflected slightly, creating the steps, when fracture had occurred around similarly oriented $\alpha$ laths.

To gain a better understanding on the nature of the terrace-like features of Fig. 11 and to verify the possibility of inter granular propagation mechanism, EBSD was carried out on a plane parallel and close to the fracture surface of one of the terrace-like feature (Fig. 12a-b). Fig. 12c shows $\alpha$ orientation map corresponding to the selected feature and the corresponding reconstructed parent $\beta$ phase. It was observed that the terrace feature is made of several $\alpha$ laths with repeating crystal orientations as typical of the variants found within one prior- $\beta$ columnar grain [27]. The analysis of the orientation of the $\alpha$ laths (Fig. 12d) indicates the fracture has occurred in none of the basal or prismatic planes that are instead generally associated with $\alpha$ cleavage fracture $[30,40,51]$. In addition, the reconstruction of the parent $\beta$ phase shows that all these $\alpha$ laths have originated from one unique grain. Finally as shown in Fig. 12a, the fracture surfaces do not show any of the elongated cylindrical dimples (generally referred to as "flutes") that typically form with lamellar fracture in $\alpha+\beta$ Ti alloys 
$[46,51,52]$. As evidenced from both fracture surface profiles and the obtained EBSD results, the predominant fracture in SLM Ti-6Al-4V is inter granular fracture, thus it is believed that terrace-like features that appear on the fracture surfaces might have originated upon crack propagation through prior $\beta$ grains, predominantly along $\alpha$ grain boundaries.

The early crack propagation during tensile overload was also investigated in one vertical oriented tensile bar that was pulled until the onset of necking (the test was interrupted at a stress level of about $1100 \mathrm{MPa}$ and corresponding elongation of 8\%). Fig. 13a-b show several microvoid observed in the microstructure of the plastically deformed sample. Although it is not possible to establish with accuracy whether the microvoid had originated from pre-existing pores or in correspondence of $\alpha$ lath fracture, Fig. 13a-b suggest that the microvoids tend to propagate along the $\alpha$ grain boundaries at the early stage of fracture, as observed in other $\alpha+\beta$ Ti alloys with fine microstructure [30].

\section{Conclusion}

This work has investigated the tensile properties of the near fully dense SLM Ti-6Al-4V parts. In particular, the objective of the present research was to discuss the tensile properties of the as-built and stress relieved SLM Ti-6Al-4V samples. The fracture mechanism of bars built in different orientations (flat, edge and vertical orientations) was then compared to establish the anisotropy propterty of the parts.

The evidence presented in this study suggests that:

1) the ductility of SLM Ti-6Al-4V is dependent on the build orientation of the parts. In particular, the edge oriented bars showed the best tensile properties and the greatest elongation at fracture. 
2) the results presented in this study indicate that the directionality of the microstructure affects the fracture mechanisms and the crack propagation in the parts. It was found that the fracture surface profiles differ with the build orientation because of the orientation of prior- $\beta$ grain boundaries to the external axial loading direction. The lack of a strong texture in SLM Ti-6Al-4V and the absence of $\alpha$ colonies explain why the dominant fracture mode is intergranular $\alpha$ and along the prior- $\beta$ grain boundaries.

3) regardless of the build orientation, the stress relief heat treatment alters the phase composition of the samples and has a significant effect on the tensile properties of the bars. In particular, the martensitic $\alpha^{\prime}$ phase of the as-built samples evolves into a mixture of $\alpha+\beta$ phase. It is possible, therefore, that in the stress relieved samples, slip transfer can take place across the $\alpha / \beta$ interface, hence increasing the overall ductility of the samples. In addition, high residual stresses $(\sim 300 \mathrm{MPa})$ were measured in the as-built bars suggesting that stress relief of the parts might be required to avoid any potential part distortion. 


\section{References}

[1] F.G. Arcella, F. Froes, JOM, 52 (2000) 28-30.

[2] P. Kobryn, S. Semiatin, JOM, 53 (2001) 40-42.

[3] M. Baumers, C. Tuck, R. Hague, I. Ashcroft, R. Wildman, Solid Freeform Fabrication Symposium, 2010.

[4] P. Reeves, C. Tuck, R. Hague, Mass Customization, (2011) 275-289.

[5] I. Gibson, D.W. Rosen, B. Stucker, Additive manufacturing technologies, Springer, 2010.

[6] N. Hopkinson, R. Hague, P. Dickens, Rapid manufacturing: an industrial revolution for the digital age, John Wiley \& Sons, 2006.

[7] L.S. Bertol, W.K. Júnior, F.P.d. Silva, C. Aumund-Kopp, Materials \& Design, 31 (2010) 3982-3988.

[8] P. Heinl, L. Müller, C. Körner, R.F. Singer, F.A. Müller, Acta biomaterialia, 4 (2008) $1536-1544$.

[9] M. Wehmöller, P. Warnke, C. Zilian, H. Eufinger, International Congress Series, Elsevier, 2005, 690-695.

[10] D. Brackett, I. Ashcroft, R. Hague, Solid Freeform Fabrication Symposium, 2011, 348362.

[11] R. Dehoff, C. Duty, W. Peter, Y. Yamamoto, W. Chen, C. Blue, C. Tallman, Advanced Materials \& Processes, 171 (2013) 19-22.

[12] R. Hasan, R. Mines, P. Fox, Procedia Engineering, 10 (2011) 536-541.

[13] S. Rawal, J. Brantley, N. Karabudak, Recent Advances in Space Technologies (RAST), 2013 6th International Conference, 2013, 5-11.

[14] L. Thijs, F. Verhaeghe, T. Craeghs, J.V. Humbeeck, J.-P. Kruth, Acta Materialia, 58 (2010) 3303-3312.

[15] L. Facchini, E. Magalini, P. Robotti, A. Molinari, S. Höges, K. Wissenbach, Rapid Prototyping Journal, 16 (2010) 450-459.

[16] B. Vrancken, L. Thijs, J.-P. Kruth, J. Van Humbeeck, Journal of Alloys and Compounds, 541 (2012) 177-185.

[17] H. Attar, M. Calin, L. Zhang, S. Scudino, J. Eckert, Materials Science and Engineering: A, 593 (2014) 170-177.

[18] D. Gu, Y.-C. Hagedorn, W. Meiners, G. Meng, R.J.S. Batista, K. Wissenbach, R.

Poprawe, Acta Materialia, 60 (2012) 3849-3860.

[19] C. Qiu, N.J. Adkins, M.M. Attallah, Materials Science and Engineering: A, 578 (2013) 230-239.

[20] B. Song, S. Dong, B. Zhang, H. Liao, C. Coddet, Materials \& Design, 35 (2012) 120125.

[21] E. Chlebus, B. Kuźnicka, T. Kurzynowski, B. Dybała, Materials Characterization, 62 (2011) 488-495.

[22] T. Sercombe, N. Jones, R. Day, A. Kop, Rapid Prototyping Journal, 14 (2008) 300-304.

[23] T. Vilaro, C. Colin, J.D. Bartout, Metallurgical and Materials Transactions A, 42 (2011) 3190-3199.

[24] H. Rafi, N. Karthik, H. Gong, T.L. Starr, B.E. Stucker, Journal of Materials Engineering and Performance, 22 (2013) 3872-3883.

[25] P. Edwards, M. Ramulu, Materials Science and Engineering: A, 598 (2014) 327-337.

[26] M. Simonelli, Y.Y. Tse, C. Tuck, Supplemental Proceedings: Materials Processing and Interfaces, 1 (2012) 863-870.

[27] M. Simonelli, Y.Y. Tse, C. Tuck, Metallurgical and Materials Transactions A, (2014) 110.

[28] G. West, R. Thomson, Journal of microscopy, 233 (2009) 442-450. 
[29] B.D. Cullity, American Journal of Physics, 25 (1957) 394-395.

[30] D. Banerjee, J. Williams, Acta Materialia, 61 (2013) 844-879.

[31] G. Lütjering, Materials Science and Engineering: A, 243 (1998) 32-45.

[32] T. Mohandas, D. Banerjee, V.K. Rao, Metallurgical and Materials Transactions A, 30

(1999) 789-798.

[33] I. Yadroitsev, P. Bertrand, I. Smurov, Applied surface science, 253 (2007) 8064-8069.

[34] M.J. Donachie, Titanium: a technical guide, ASM international, 2000.

[35] P. Kobryn, S. Semiatin, Solid Freeform Fabrication Symposium, 2001, 6-8.

[36] L. Facchini, E. Magalini, P. Robotti, A. Molinari, Rapid Prototyping Journal, 15 (2009) 171-178.

[37] R. Boyer, E. Collings, Materials properties handbook: titanium alloys, ASM

International, 1994.

[38] L. Murr, S. Quinones, S. Gaytan, M. Lopez, A. Rodela, E. Martinez, D. Hernandez, F. Medina, R. Wicker, Journal of the mechanical behavior of biomedical materials, 2 (2009) 2032.

[39] D. Bhattacharyya, G. Viswanathan, R. Denkenberger, D. Furrer, H.L. Fraser, Acta materialia, 51 (2003) 4679-4691.

[40] A. Pilchak, J. Williams, Metallurgical and Materials Transactions A, 42 (2011) 10001027.

[41] S. Leuders, M. Thöne, A. Riemer, T. Niendorf, T. Tröster, H. Richard, H. Maier, International Journal of Fatigue, 48 (2013) 300-307.

[42] P. Mercelis, J.-P. Kruth, Rapid Prototyping Journal, 12 (2006) 254-265.

[43] M. Shiomi, K. Osakada, K. Nakamura, T. Yamashita, F. Abe, CIRP Annals-

Manufacturing Technology, 53 (2004) 195-198.

[44] C. Casavola, S. Campanelli, C. Pappalettere, The Journal of Strain Analysis for

Engineering Design, 44 (2009) 93-104.

[45] W.J. Yuan, Z.L. Zhang, Y.J. Su, L.J. Qiao, W.Y. Chu, Materials Science and Engineering: A, 532 (2012) 601-605

[46] C.R. Brooks, A. Choudhury, Failure analysis of engineering materials, McGraw-Hill New York, 2002.

[47] B. Baufeld, E. Brandl, O. Van der Biest, Journal of Materials Processing Technology, 211 (2011) 1146-1158.

[48] R. Nalla, B. Boyce, J. Campbell, J. Peters, R. Ritchie, Metallurgical and Materials Transactions A, 33 (2002) 899-918.

[49] J. Chesnutt, C. Rhodes, J. Williams, Fractography--Microscopic Cracking Processes, (1976) 99-138.

[50] N. Hrabe, T. Quinn, Materials Science and Engineering: A, 573 (2013) 271-277.

[51] A. Pilchak, J. Williams, Metallurgical and Materials Transactions A, 41 (2010) 22-25.

[52] D.A. Meyn, R.A. Bayles, Fractography of Modern Engineering Materials: Composites and Metals, Philadephia, 1987, 400-424. 
Table 1

Process Parameters

\begin{tabular}{cc}
\hline Laser Power $[\mathrm{W}]$ & 157 \\
Layer Thickness $[\mu \mathrm{m}]$ & 50 \\
Point Distance $[\mu \mathrm{m}]$ & 45 \\
Exposure Time $[\mu \mathrm{s}]$ & 200 \\
Hatch Spacing $[\mu \mathrm{m}]$ & 100 \\
Scan Speed $[\mathrm{mm} / \mathrm{s}]$ & 225 \\
Oxygen Concentration $[\%]$ & 0.3 \\
Laser Spot Size $[\mu \mathrm{m}]$ & 150
\end{tabular}

Table 2

Surface Roughness Ra [ $\mu \mathrm{m}]$

As-built lateral surfaces - yz plane 28.587

As-built top surface -xy plane 6.834

After polishing - all surfaces 0.395

Table 3

Tensile properties of SLM Ti-6Al-4V in the as-built condition, four test samples per each build orientation.

\begin{tabular}{lcccc}
\hline & E [Gpa] & $\boldsymbol{\sigma}_{\mathbf{y}}$ [Mpa] & UTS [Mpa] & $\boldsymbol{\varepsilon}$ fracture [\%] \\
$\mathrm{XZ}$ & $115 \pm 6$ & $978 \pm 5$ & $1143 \pm 6$ & $11.8 \pm 0.5$ \\
$\mathrm{ZX}$ & $119 \pm 7$ & $967 \pm 10$ & $1117 \pm 3$ & $8.9 \pm 0.4$ \\
$\mathrm{XY}$ & $113 \pm 5$ & $1075 \pm 25$ & $1199 \pm 49$ & $7.6 \pm 0.5$
\end{tabular}

Tensile properties of SLM Ti-6Al-4V in the stress relieved condition, four test samples per each build oreintaion.

$\begin{array}{lcccc} & \text { E [Gpa] } & \boldsymbol{\sigma}_{\mathbf{y}} \text { [Mpa] } & \text { UTS [Mpa] } & \boldsymbol{\varepsilon} \text { fracture [\%] } \\ \mathrm{XZ} & 113 \pm 9 & 958 \pm 6 & 1057 \pm 8 & 12.4 \pm 0.7 \\ \mathrm{ZX} & 117 \pm 6 & 937 \pm 9 & 1052 \pm 11 & 9.6 \pm 0.9 \\ \mathrm{XY} & 112 \pm 6 & 974 \pm 7 & 1065 \pm 21 & 7.0 \pm 0.5\end{array}$


Table 4

Point stress tensor on the middle of the frontal plane of an as-built sample

$\begin{array}{ccc}182 & -239 & 243 \\ -188 & 243 & 0\end{array}$


